\title{
Commentary: Off-pump transapical neochord implantation-An added tension in the operating room
}

\author{
Edward D. Percy, MD, a,b and Sary F. Aranki, MD
}

\footnotetext{
From the a Division of Cardiac Surgery, Department of Surgery, Brigham and Women's Hospital, Harvard Medical School, Boston, Mass; and ${ }^{\mathrm{b}}$ Division of Cardiovascular Surgery, University of British Columbia, Vancouver, British Columbia, Canada.

Disclosures: Authors have nothing to disclose with regard to commercial support.

Received for publication May 15, 2019; accepted for publication May 16, 2019; available ahead of print June 27, 2019.

Address for reprints: Sary F. Aranki, MD, Brigham and Women's Hospital, 75 Francis St, Boston, MA 02115 (E-mail: saranki@partners.org).

J Thorac Cardiovasc Surg 2019;158:756-7

$0022-5223 / \$ 36.00$

Copyright (c) 2019 by The American Association for Thoracic Surgery

https://doi.org/10.1016/j.jtcvs.2019.05.030
}

Surgical mitral valve repair is an effective, gold-standard treatment for patients with severe degenerative mitral valve disease. ${ }^{1}$ The success of this procedure has led to the development of several technologies that seek to reproduce durable repairs while minimizing surgical trauma and avoiding the adverse effects of cardiopulmonary bypass. ${ }^{2}$ Recently, transapical chordal implant devices have shown success in their ability to mimic open chordal repairs in selected patients. ${ }^{3,4}$ In this edition of the Journal, Grinberg and colleagues ${ }^{5}$ describe a device used in conjunction with transesophageal echocardiography for measurement of chordal tension and assessment of repair. ${ }^{5}$

The word art is often used in reference to the complexity and variability of mitral repair techniques. The emergence of chordal replacement in the past 2 decades has offered a chance for new tools to be added to already existing repair strategies; however, approaches to chordal placement and measurement continue to vary widely. ${ }^{6}$ With a novel, purpose-built device, Grinberg and colleagues ${ }^{5}$ performed real-time force measurements on transapically implanted neochordae in 7 high-risk patients with posterior leaflet prolapse. Their device allows both precise measurement and control of chordal tension during off-pump implantation. They report good clinical outcomes with systematically setting the tension of individual chords under transesophageal echocardiographic guidance. Furthermore, they provide new insights into the mechanical characteristics of successful mitral repair: First, the overall tension experienced by implanted neochords is relatively low $(0.8$ to $1 \mathrm{~N}$ force). Second, the overall tension of the repair is distributed evenly, such that the force on each neochord is approximately equal, and inversely proportional to the total number of neochords implanted. Third, the tension experienced by the implanted chords is minimized when an echocardiographically successful repair is achieved.

These interesting findings must be taken in proper context, as a preliminary study of a complex and potentially time-consuming system. The sample included only 7

\section{References}

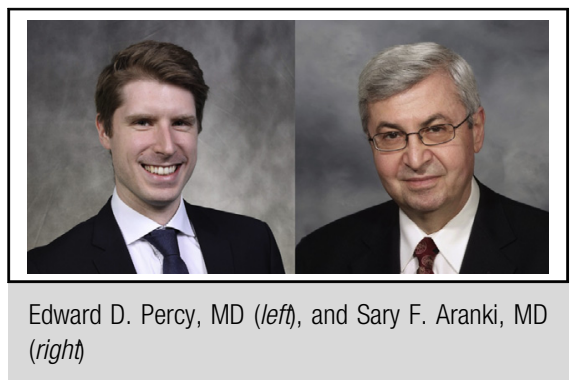

Central Message

Measurement of chordal tension during transapical implantation provides important clues about the mechanics of successful mitral repair.

See Article page 746.

patients, all of whom were carefully selected high-risk surgical candidates. Furthermore, this study did not show an advantage relative to traditional repair rate, given the recurrence of moderate mitral regurgitation in 1 of 7 patients at 30 days. The left ventricular diastolic dimensions in this population (mean, $59.5 \mathrm{~mm}$; range, $55-63 \mathrm{~mm}$ ) may also limit generalizability to patients with other left ventricular geometries. Finally, as with any mitral technique, final assessment remains limited by intraoperative anesthetic conditions and long-term outcomes.

Despite these limitations, Grinberg and colleagues ${ }^{5}$ have given us a "first look" at the tension experienced by implanted chords in a beating human heart. More study in this field may lead to further standardization in mitral surgery, with a focus on optimizing the mechanical properties of a repair in addition to visual assessments. Grinberg and colleagues ${ }^{5}$ are to be commended for an interesting article and for striving to add more science to the art of mitral valve repair.

1. Nishimura RA, Otto CM, Bonow RO, Carabello BA, Erwin JP III, Fleisher LA, et al. 2017 AHA/ACC focused update of the 2014 AHA/ACC guideline for the management of patients with valvular heart disease: a report of the American College of Cardiology/American Heart Association Task Force on Clinical Practice Guidelines. J Am Coll Cardiol. 2017;70:252-89.

2. D'Onofrio A, Gerosa G. Shifting a paradigm of cardiac surgery: from minimally invasive to micro-invasive. J Heart Valve Dis. 2015;24:528-30.

3. Colli A, Manzan E, Aidietis A, Rucinskas K, Bizzotto E, Besola L, et al. An early European experience with transapical off-pump mitral valve repair with NeoChord implantation. Eur J Cardiothorac Surg. 2018;54:460-6. Erratum in: Eur J Cardiothorac Surg. 2019;55:1240. 
4. Gammie JS, Wilson P, Bartus K, Gackowski A, Hung J, D'Ambra MN, et al. Transapical beating-heart mitral valve repair with an expanded polytetrafluoroethylene cordal implantation device. Circulation. 2016;134:189-97.

5. Grinberg D, Cottinet P-J, Thivolet S, Audigier D, Capsal J-F, Le M-Q, et al. Measuring chordae tension during transapical neochordae implantation: toward understanding objective consequences of mitral valve repair. J Thorac Cardiovasc Surg. 2019;158:746-55.

6. Ibrahim M, Rao C, Athanasiou T. Artificial chordae for degenerative mitral valve disease: critical analysis of current techniques. Interact Cardiovasc Thorac Surg. 2012;15:1019-32. 